\title{
EL CARÁCTER PRIVADO \\ DEL PROCESO DE INAPLICABILIDAD POR INCONSTITUCIONALIDAD*
}

["The Private Nature of the Process of Non-Applicability Due to

Unconstitutionality"]

\section{Alan Bronfman** \\ Pontificia Universidad Católica de Valparaíso, Chile}

\begin{abstract}
Resumen
El proceso de inaplicabilidad debe su estructura al modelo tradicional de litigación privada. En su seno acoge el trámite de un recurso que también nace de un litigio construido siguiendo el modelo de proceso privado. En este artículo se examinan algunas de las dificultades que surgen del uso de este modelo en un proceso de control concreto de constitucionalidad que contienes intereses y objetivos que se distancian de la litigación privada.

Palabras clave

Inaplicabilidad - proceso - Control concreto de constitucionalidad - litigación privada - litigación pública.
\end{abstract}

\begin{abstract}
The structure of the non-applicability process is based on the traditional model of private litigation. It includes the formalities of a motion that also arises from a litigation built on the basis of the private process model. This article analyzes some of the difficulties arising from the use of this model in a specific judicial review process that has interests and objectives away from the private litigation.

\section{KEYWORDS}

Non-applicability - process - Specific judicial review - private litigation - public litigation.
\end{abstract}

[RECIBIDO el 7 y ACEPTADo el 28 de octubre de 2011].

* Este artículo forma parte del proyecto Fondecyt 1090607: “Sujeto, objeto y decisión en la cuestión de inaplicabilidad: formulación del marco de principios procesales constitucionales que encuadran el control concreto de constitucionalidad de la legislación y la jurisdicción tras la reforma de la Ley $\mathrm{N}^{\circ} 20.050^{\prime}$, en el cual el autor es coinvestigador.

** Doctor en Derecho por la Universidad de Santiago de Compostela, España; profesor de Derecho constitucional de la Facultad de Derecho de la Pontificia Universidad Católica de Valparaíso. Dirección postal: Facultad de Derecho, Pontificia Universidad Católica de Valparaíso, Avda. Brasil 2950, Valparaíso, Chile. Correo electrónico: alan. bronfman@ucv.cl. 
El presente artículo examina el proceso de inaplicabilidad por inconstitucionalidad contrastando sus funciones y los intereses que acoge con las reglas que lo configuran. Este contraste permite comprender la insuficiencia de las reglas típicas de una litigación que confronta intereses privados e intuir la necesidad de sumar reglas propias de otro tipos de procesos decisorios públicos.

La regulación del recurso de inaplicabilidad tiene tras de sí una evolución histórica condicionada de manera importante por las razones políticas amparadas en la doctrina de separación de poderes ${ }^{1}$. De ahí que sea conveniente examinar las funciones que cumple y los intereses que lo impulsan, de modo de asegurar que las reglas que lo gobiernan sirvan para los propósitos que justifican su existencia.

\section{LAS FUNCIONES DEL CONTROL JURISDICCIONAL DE CONSTITUCIONALIDAD DE LA LEY DESDE UNA PERSPECTIVA EXTERNA}

La constitución contiene un conjunto de opciones políticas convertidas en principios jurídicos y reglas que determinados grupos o sectores de la sociedad defienden como esenciales para el funcionamiento de la comunidad política. Una de las vías para lograr la defensa de las opciones políticas contenidas en la constitución (o de asegurar su supremacía, si se prefiere) es el control de constitucionalidad encargado a órganos de naturaleza judicial.

Las modalidades de control jurisdiccional de constitucionalidad que se adopten han de ajustarse a la realidad política e histórica de cada comunidad política. Factores tales como la mayor o menor densidad ideológica de la constitución, su reformabilidad, su legitimidad política y social, la tradición judicial existente, los rasgos culturales de sociedad, el funcionamiento efectivo de los frenos y contrapesos, el nivel de desarrollo y cultivo del Derecho son esenciales en la determinación de un buen y operativo sistema de control de constitucionalidad.

\footnotetext{
${ }^{1}$ En concreto, el interés democrático que busca limitar el poder de autoridades no elegidas para dejar sin efecto una decisión adoptada por autoridades representativas, como son diputados, senadores y presidente de la república. En la subcomisión que debatió el texto constitucional de 1925 se mencionó el ejemplo de otros países que a la fecha contaban con control de constitucionalidad difuso (como Argentina), criticándose el poder que estas atribuciones otorgaban a los jueces; MINISTERIO DEL INTERIOR, Actas Oficiales del Proyecto de Nueva Constitución Política de la República (Santiago, Imprenta Universitaria, 1926). Si el pronunciamiento tuviese un efecto general, la atribución transformaría al Tribunal Supremo en un Poder Legislador y la facultad perdería su carácter propiamente judicial que lo obliga a resolver el conflicto que se somete a su conocimiento; Silva Bascuñán, Alejandro, Tratado de Derecho constitucional (Santiago, Editorial Jurídica de Chile, 1963), III, p. 445.
} 
La decisión de instaurar el control jurisdiccional de constitucionalidad exige optar por alguna de sus modalidades y, en este sentido, es menester conocer cuál es la utilidad de cada una.

En el listado de posibles contribuciones al régimen constitucional de un modelo de control abstracto expost debemos mencionar su aptitud para mejorar la adhesión e integración al sistema político de grupos o comités parlamentarios de oposición, siempre que éstos puedan acceder al órgano jurisdiccional y siempre que éste tenga capacidad para imponer sus sentencias a la mayoría gobernante ${ }^{2}$. En particular, en comunidades políticas que no han logrado un consenso suficiente sobre las reglas que han de regir a las instituciones de gobierno, el control de constitucionalidad de base abstracta puede ser un buen pie apoyo para la vigencia efectiva de una constitución mínima. La jurisdicción constitucional tiene en sus manos la posibilidad de fortalecer los rasgos integradores de una carta fundamental que exhibe una legitimación política y social débil o incipiente. Por ende, el buen ejercicio del control de constitucionalidad puede mejorar la expectativa de pervivencia en el tiempo de la constitución, ya que controles contramayoritarios adecuados refuerzan la legitimidad de las instituciones políticas. Lo anterior sin perjuicio que la resistencia a la voluntad política de la mayoría puede generar conflictos que terminen disminuyendo el poder efectivo del órgano contralor y por lo tanto su capacidad de impedir que la autoridad gobernante subvierta la constitución mediante la ley ${ }^{3}$.

La otra cara de la moneda es el ejercicio de la potestad de control de constitucionalidad en su modalidad abstracta conforme con los intereses de la mayoría gobernante. En tal caso se observa un fenómeno que Tsbelis denomina de absorción y que disminuye de manera significativa el potencial aporte del órgano contralor de constitucionalidad en el sistema político ${ }^{4}$.

${ }^{2}$ Parte de la doctrina española ha entendido que la posibilidad de plantear una cuestión abstracta de constitucionalidad permite a la minoría parlamentaria invocar la Constitución para hacer valer razones desatendidas por la mayoría que aprueba la ley. Véanse: CaAmaño Dominguez, Francisco - Gómez Montoro, Ángel J. - Medina Guerrero, Manuel - Requejo Pagés, Juan Luis, Jurisdicción y procesos constitucionales (Madrid, McGraw-Hill, 1997), p. 19.

${ }^{3}$ En democracias nuevas el triunfo de la justicia constitucional sobre el poder político no está asegurado. Una forma directa de menoscabar su poder es la destitución de sus integrantes. Una forma indirecta de menoscabar su poder es el nombramiento de jueces sometidos a los intereses partidistas. En febrero del año 2010, el Tribunal Constitucional boliviano dejó de funcionar por no contar con ninguno de sus cinco ministros titulares ni suplentes, situación de vacancia que se arrastró por años y cuyo origen, como no, es un conflicto con el partido político gobernante.

${ }^{4}$ Tsebelis, George, Veto Players: How Political Institutions Work (Princeton, Princeton University Press, 2002), p. 227: "En tanto los jueces constitucionales tienen 
Un modelo de control concreto expost de constitucionalidad, por su parte, puede ser útil para depurar el ordenamiento jurídico de normas contrarias a la constitución, siguiendo los intereses que afloran de la propia sociedad ${ }^{5}$. La legitimación activa que se otorga en este modelo a particulares, aunque tenga importantes restricciones, permite hacer más viva la constitución en la sociedad, pues permite asociarla a la solución de problemas concretos que dan origen a litigios, problemas que el legislador no ha previsto o ha tratado de manera incorrecta, o no ha querido o no ha podido resolver ${ }^{6}$. En esta línea, Sabel y Simon sostienen que el proceso originado en el control concreto de constitucionalidad permite privar de fundamento jurídico a instituciones que han fallado en cumplir sus obligaciones básicas y que permanecen inmunes a las tradicionales vías de enmienda por parte de órganos políticos ${ }^{7}$.

El hecho que el control concreto de constitucionalidad sea una herramienta útil, no impide reconocer su mal acomodo en la separación de poderes. En el control concreto el interés constitucional prima sobre el democrático en tanto las instituciones que lo encarnan han fallado en su sumisión a la norma fundamental. En la práctica, es claro que el ejercicio del control de constitucionalidad de base concreta puede mermar la capacidad de gobernar, imponiendo la voluntad de los jueces constitucionales sobre el consenso político expresado en la ley.

Ambos modelos de control jurisdiccional de constitucionalidad resultan modulados por las ideas y doctrinas de las personas nombradas jueces constitucionales y su estatuto orgánico, como también por las reglas que establecen el procedimiento. El procedimiento puede acrecentar o morigerar las notas

poderes de veto, la mayoría de las veces son absorbidos" y dominados por los intereses de los partidos políticos. La absorción induce a los jueces constitucionales a comportarse del mismo modo que la mayoría gobernante.

${ }^{5}$ Sin perjuicio que ellos puedan ser recogidos y cohesionados por grupos políticos o sociales. No es infrecuente que el interés particular sea absorbido por una organización y convertido en una bandera para lograr un objetivo político más amplio (cfr. con la trastienda de "Roe v. Wade"). Los costos de la litigación constitucional en instancias superiores en los Estados Unidos hacen muy tentador para las partes litigantes el apoyo ofrecido por organizaciones sin fin de lucro dotadas de su propia agenda política legislativa.

${ }^{6}$ El listado de causas, por cierto, se plantea sólo a vía ejemplar. En el caso de resultados no previstos por el legislador que causan un daño no amparado por la constitución, la generalidad de la ley explica en parte que los parlamentarios no sean capaces de predecir todos los efectos de la ley que aprueban. El tribunal constata un efecto no previsto y ahí aflora una razón para realizar un examen de constitucionalidad dotado de una finalidad remedial no política. Para las autoridades elegidas, la posibilidad que los jueces resuelvan cuestiones políticas controvertidas no es siempre indeseada.

${ }^{7}$ Sabel, Charles F. - Simon, William H., Destabilization Rights: How Public Law Litigation Succeeds, en Harvard Law Review, 117 (febrero de 2004) 4, p. 1020. 
distintivas de la relación entre control de constitucionalidad y gobierno. La duración del proceso o el tiempo medio que transcurre entre la constatación de la inconstitucionalidad y la invalidación de la norma, por ejemplo, condicionan de manera significativa la inserción del control jurisdiccional de constitucionalidad en el sistema político y su incidencia en el desarrollo de la agenda política y legislativa del partido o coalición gobernante ${ }^{8}$.

\section{EL MODELO DE CONTROL JURISDICCIONAL} DE CONSTITUCIONALIDAD CONCRETO

Y EL MODELO DE CONTROL JURISDICCIONAL ABSTRACTO

El primer modelo control de constitucionalidad de la ley es el desarrollado por la Corte Suprema norteamericana a partir de "Marbury versus Madison", en los inicios del siglo XIX ${ }^{9}$. Aunque alguno de los elementos relevantes del modelo son fruto de una lenta construcción jurisprudencial y doctrinal, los autores lo caracterizan desde un inicio como un control de tipo concreto. La concreción del "judicial review" surgió del uso de un litigio que se conoce en un proceso ordinario como base para el examen de la constitucionalidad de una norma legal aplicable a su solución.

En el modelo norteamericano, la revisión judicial se radica en el poder judicial y no funciona de manera distinta de los restantes modos de impartir justicia. Todos los litigios, cualquiera sea su naturaleza, son decididos por los mismos tribunales, los mismos procedimientos y en circunstancias similares ${ }^{10}$. La cuestión constitucional no recibe un tratamiento especial pues no hay razón para distinguir entre litigios que son sometidos a un mismo tribunal ${ }^{11}$.

Desde un punto de vista orgánico, el carácter difuso del control de

${ }^{8} \mathrm{Su}$ carácter reactivo, la forzosa aplicación de reglas de interpretación jurídica y su potestad invalidatoria de legislador negativo, lo conducen a un ejercicio de influencia política no creativo y, por lo tanto, limitativo de su incidencia en la agenda política. El alcance formal de la declaración de inconstitucionalidad podría tener un efecto limitativo, aunque el ejercicio del control jurisdiccional desde un órgano concentrado exhibe siempre una tendencia hacia el efecto general.

"Sin perjuicio de que Sir Edward Coke en otro caso (el "Bonham" de 1610) ya había sostenido que la ley debía ajustarse a los principios del "Common law" y que a los jueces correspondía decidir si procedía o no su aplicación: van CAENEGEM, R.C., $A n$ historical introduction to Western Constitutional Law (Cambridge, Cambridge University Press, 1996), pp. 159-160.

${ }^{10}$ JaCkson, Vicki C. - Tushnet, Mark, Comparative Constitutional Law (2a ed., Nueva York, Foundation Press, 2006), p. 470.

${ }^{11}$ La no especialización de los tribunales norteamericanos explica en parte esta respuesta, en contraste con la especialización propia de la organización judicial europea. 
constitucionalidad norteamericano no puede disociarse de la naturaleza concreta del mismo. La influencia del derecho creado por los jueces en los ordenamientos jurídicos del "Common law” está condicionada de manera significativa por la multiplicidad de fuentes (o jueces) que intermedian la aplicación de las reglas fijadas por el poder legislativo.

El caso, en este contexto, no es un mero instrumento para justificar una actividad de interpretación de la constitución por parte del juez. El examen de constitucionalidad de la ley está al servicio del litigio y sólo se entiende dentro de él, sin perjuicio de la intencionalidad que su ejercicio suponga y sin perjuicio de la posible expansión y afianzamiento del criterio de interpretación asentado. La expansión y afianzamiento del criterio de interpretación asentado tiene estricta relación con la forma en que se crea el derecho en los sistemas de "Common law" y no con el propósito de servir a la supremacía constitucional (aunque le sirva). Con todo, es claro que una herramienta jurídica formidable como la constitución puede ser empleada por los jueces como una vía para desarrollar su propia agenda ideológica y en tal caso el desasimiento de la cuestión litigiosa real es una consecuencia que algunos juristas están más que dispuestos a tolerar ${ }^{12}$.

El ejercicio del poder de revisión constitucional en el régimen norteamericano tiene un carácter relativo y se encuentra limitado por restricciones que aseguran su naturaleza concreta. Así, el artículo 3, sección segunda, párrafo primero de Constitución federal señala: "The judicial Power shall extend to all Cases, in Law and Equity, arising under this Constitution [...]”. Desde aquí se ha construido la doctrina de la justiciabilidad, que incluye las nociones de legitimación activa, madurez y conducencia ${ }^{13}$. Quien inicia el litigio debe ser una persona dañada en un interés propio, que plantea una controversia existente (no potencial) y que puede conducir a una respuesta efectiva por el tribunal ${ }^{14}$. Sin estos requisitos, que exigen un caso o controversia efectivos, los tribunales no están habilitados para conocer de un problema de constitucionalidad, lo que impide o dificulta la promoción de un control meramente ideológico.

El resultado de la interpretación constitucional de cada juez queda confinado al proceso en que se produce. Aunque el stare decisis pueda expandir esta interpretación, hay un conjunto de factores que condicionan su consolidación como precedente vinculante. Por lo pronto, las circunstancias del caso serán sopesadas por cada juez para resolver sobre la aplicabilidad de la sentencia que declara aplicable o no aplicable una determinada norma legal en razón de su

12 "Roe v. Wade" (1973) ofrece un formidable ejemplo de este desasimiento.

13 "Standing to sue, ripeness y mootness".

${ }^{14}$ Brilmayer, Lea, The Jurisprudencia of Article III: Perspectives on the "Case or Controversy" Requirement en Harvard Law Review 93 (1979) 2, pp. 297 y 298. 
constitucionalidad o inconstitucionalidad ("distinguishing"). En el fondo de la cuestión resuelta, la naturaleza de ratio decidendi o de obiter dictum es esencial para la consolidación del precedente constitucional ${ }^{15}$. También el nivel del tribunal que se pronuncia sobre la cuestión de constitucionalidad incide de manera determinante en la expectativa de su afianzamiento como precedente ${ }^{16}$. Conviene observar que en tanto una sentencia que declara la inconstitucionalidad de una norma legal no es conocida por la Corte Suprema, el criterio interpretativo que la sustenta puede ser modificado. A este respecto, subrayemos que sólo cerca del uno por ciento de los asuntos sometidos a la Corte Suprema son conocidos por ésta, lo que arroja algún grado de provisionalidad a la interpretación constitucional formulada en los restantes $\operatorname{casos}^{17}$. Incluso una vez que la Corte Suprema se ha pronunciado, es posible que ella misma modifique el precedente que ha establecido.

En suma, las restricciones asociadas al modelo concreto de control de constitucionalidad tienen importantes consecuencias en sus efectos, que refuerzan el carácter relativo de la decisión de constitucionalidad. Esta no tiene ni la fijeza ni estabilidad de una decisión legislativa o de una sentencia de control de tipo abstracto.

El segundo modelo de control de constitucionalidad es el europeo continental, cuya nota distintiva es su carácter abstracto. En el no hay un litigio que sustente y delimite la interpretación constitucional, con lo que el control exhibe su carácter político sin ningún ropaje que lo proteja o cubra. En su labor, corresponde al juez constitucional confrontar una norma legal y la constitución y de allí elaborar una interpretación que la ampare o invalide.

La tendencia europea occidental hacia la creación de tribunales especializados organizados para cada rama del derecho y la naturaleza del control abstracto, propician la implementación de un único órgano de control de constitucionalidad. La opción por una jurisdicción concentrada hace difícil evitar el efecto general resultante del control sin menoscabar la efectiva supremacía de la constitución.

El empleo de un proceso como vehículo que sustenta el ejercicio del control de constitucionalidad abstracto va de la mano con la decisión de encomendar a jueces la labor de contraste con la carta suprema. La constitución permite transformar en derecho un conjunto de valoraciones políticas

${ }^{15}$ Ruiz Miguel, Alfonso, Modelo americano y modelo europeo de justicia constitucional, en Doxa. Cuadernos de Filosofía del Derecho 23 (2000), p. 154.

${ }^{16}$ Entre más bajo sea su lugar en la organización judicial, es mayor la probabilidad de "overruling".

${ }^{17}$ Epstein, Lee - Knight, Jack - Shvetsova, Olga, The Role of Constitutional Courts in the Establishment and Maintenance of Democratic Systems of Government, en Law \& Society Review, 35 (2001) 1, p. 123. 
y propiciar su permanencia en el régimen político más allá de la potestad y autoridad de quienes la aprobaron. Los jueces y las reglas de la interpretación jurídica se han demostrado útiles para la defensa de los contenidos de las normas supremas y el proceso es la instancia donde es posible desarrollar la actividad jurídica buscada.

\section{LA LEGITIMACIÓN ACTIVA \\ EN MODELOS DE CONTROL DE CONSTITUCIONALIDAD “EX POST” Y CONCENTRADOS QUE COMBINAN CARACTERÍSTICAS DE LOS MODELOS DE TIPO CONCRETO Y ABSTRACTO}

La decisión política de atribuir a órganos jurisdiccionales facultades de control de constitucionalidad de la ley está, por lo común, apoyada en un conjunto de límites y condiciones. Este hecho dificulta la instauración de instituciones de control que sigan los modelos concreto y abstracto, difuso y concentrado, en su configuración tradicional y, si se quiere, pura. Como sabemos, el modelo concreto y difuso otorga un gran poder político a todos los jueces y puede amparar interpretaciones contrarias a los intereses de la mayoría gobernante ${ }^{18}$. El modelo abstracto y concentrado, por otro lado, traslada el poder político de la jurisdicción constitucional a un conjunto menos numeroso de jueces, los que pueden imponer su interpretación de la constitución por sobre los intereses de la mayoría gobernante sin las restricciones que circunscriben su actuar a un litigio particular. El órgano de control se transforma entonces en un trofeo que todos los partidos políticos y grupos de influencia quieren obtener o al menos neutralizar.

La insuficiencia de la separación de poderes para la defensa de la constitución, fuerza la incorporación al sistema político de mecanismos de control de constitucionalidad. Esta incorporación ha de subsanar o atemperar los aspectos de la actividad de control que generan mayor conflicto o dificultad en los agentes o titulares de los órganos políticos.

El inicio del proceso de control de constitucionalidad de la ley una vez que ha entrado en vigor es una de las cuestiones que puede suscitar una controversia

\footnotetext{
${ }^{18} \mathrm{Sin}$ perjuicio que los propios tribunales pueden utilizar técnicas para "reducir los costos de la decisión y el riesgo de cometer errores" y al mismo tiempo favorecer "una buena relación entre las decisiones de la justicia y la deliberación democrática”. Sola, Juan Vicente, Control judicial de constitucionalidad (Buenos Aires, Abeledo-Perrot, 2001), pp. 223-224, menciona la doctrina de la decisión mínima, que guarda armonía con los principios tradicionales de la jurisdicción constitucional: los tribunales no deben decidir temas innecesarios para la solución de un caso, los tribunales deben respetar los precedentes, los tribunales no deben elaborar opiniones consultivas, los tribunales debe seguir la ratio decidendi de los precedentes y no los obiter dicta, etc.
} 
política importante. La ley vigente, en un régimen democrático, expresa un consenso político presente o pasado, que articula un conjunto de intereses y constituye una solución o respuesta estatal ante un problema o necesidad social ${ }^{19}$. El cuestionamiento de la constitucionalidad de la ley puede destruir el consenso logrado y la articulación de intereses construida, como también demoler la solución o respuesta estatal existente ${ }^{20}$. Desde este punto de vista, las consecuencias políticas, económicas y sociales de la declaración de inconstitucionalidad de una ley pueden ser más gravosas que tolerar una vulneración de la carta suprema y nuestro Tribunal Constitucional así lo ha reconocido ${ }^{21}$.

La cuestión del inicio del control puede plantearse como un problema de legitimación activa. La legitimación activa, en este contexto, es la "capacidad de activar, o de poner en marcha, un proceso constitucional concreto"22. La egulación de la legitimación activa permite delimitar el poder de revisión de la jurisdicción constitucional y acoplar o desacoplar su ejercicio con las necesidades y demandas del sistema político. Una legitimación activa sin

${ }^{19}$ La búsqueda del consenso necesario para la aprobación de la ley, en la oportunidad que éste ofrece un beneficio o ganancia política, desplaza a un segundo plano el interés de los parlamentarios por la interpretación de la Constitución. Como juez y ex parlamentario, Abner Mikva reconoce que los parlamentarios norteamericanos tienden a aceptar los juicios de constitucionalidad que provienen de los especialistas y asesores, lo que traspasa a la justicia constitucional el deber de velar por la vigencia efectiva de la carta suprema: Tushnet, Mark, Taking the Constitution Away from the Courts (Princeton, Princeton University Press, 1999), pp. 54-55.

${ }^{20}$ Bellamy, Richard, Political Constitutionalism (Cambridge, Cambridge University Press, 2007), pp. 15-51, sostiene que la revisión judicial distorsiona la democracia y no en sus márgenes, sino en cuestiones centrales. Entiende que da origen a problemas en los asuntos que pretende resolver. Por lo mismo propone reemplazar el "legal constitutionalism" por el "political constitutionalism”. Su crítica tiene un importante aliado en Mark Tushnet.

${ }^{21}$ La sentencia del Tribunal Constitucional $\mathrm{N}^{\circ}$ 558(590)/2006, de 5 de junio de 2007, en su considerando $19^{\circ}$ señala: “[...] La exclusión de una norma legal es consecuencia de la ruptura de ese ordenamiento, para restablecerlo en plenitud. Dich a finalidad no se logra si la expulsión del precepto legal puede acarrear efectos aún más nocivos que los que produce su pervivencia. Una decisión de tal envergadura requiere, pues, la ponderación de su conveniencia para el orden constitucional que esta Magistratura debe cautelar. El criterio adecuado para calificarlo es la determinación de las consecuencias de la desaparición del precepto legal. Si deviene una situación más perjudicial o negativa que la preexistente a su anulación, no resulta conveniente para el interés público y la plena vigencia del Estado de Derecho la derogación de la norma".

${ }^{22}$ Torres Muro, Ignacio, La legitimación en los procesos constitucionales (Madrid, Reus, 2007), p. 25. Este autor destaca las dificultades que suscita el concepto que llevan a otros autores a enfatizar que esta legitimidad se reduce a un derecho a acceder a la jurisdicción constitucional o bien a la capacidad para ser parte principal en un proceso constitucional. 
restricciones (v. gr. acción pública para cuestionar la constitucionalidad de una norma legal ${ }^{23}$ ) podría mermar la capacidad de fijar la agenda de gobierno por parte de los titulares de poder representativo, al permitir cuestionar normas legales relevantes para el funcionamiento de la comunidad política (tributarias, de amnistía, internacionales, etc.) en toda oportunidad. Por otro lado, una legitimación activa restrictiva para el ejercicio del control de constitucionalidad ex post puede menoscabar la influencia del órgano contralor y dejar impune la vulneración de los mandatos constitucionales. La experiencia demuestra que los cambios en la legitimación activa generan profundas transformaciones en la jurisdicción constitucional ${ }^{24}$.

Ahora bien, en el campo de los procesos de control de constitucionalidad $a$ posteriori de la ley pueden concebirse tres posibilidades de legitimación activa: la de los titulares de órganos políticos, la de jueces y la de particulares.

La constitución puede otorgar a los titulares de órganos políticos (presidente o primer ministro, mayoría o minoría parlamentaria) la facultad de promover un examen de constitucionalidad de normas legales ${ }^{25}$. En tanto representantes y tratándose de control expost, ha de asociarse esta facultad a un examen de tipo abstracto y concentrado. Aunque el fundamento formal de la acción ejercida sea la defensa de la constitución, primará en su ejercicio la defensa del interés político propio. La utilización del proceso de control dependerá en buena medida del número de puertas que el régimen constitucional deje abiertas a la minoría política y el lugar dónde éstas conduzcan.

Con este tipo de legitimación activa, la actividad de la jurisdicción constitucional queda condicionada a las necesidades inmediatas de las instituciones políticas de gobierno. Parece inevitable que aflore en el debate el

\footnotetext{
${ }^{23}$ Como la que propusieron Licinio de la Fuente y Raúl Morodo en el proceso constituyente español de 1978: diez mil ciudadanos y doscientos mil electores. Ante esta propuesta se cuestionó la extrema inseguridad jurídica que podría generar, la demagogia que estimularía y la interferencia sistemática en la actividad legislativa de la Cortes, además del riesgo de esterilización de la labor del Tribunal Constitucional por acumulación de recursos interpuestos por grupos ciudadanos minoritarios y organizados. TORres Muro, Ignacio, cit. (n. 14), pp. 31-32.

${ }^{24}$ Ejemplo de este tipo de cambios son la reforma de la Constitución francesa del año 1974. También el traslado de la inaplicabilidad de la Corte Suprema al Tribunal Constitucional, con sus normas de legitimación activa.

${ }^{25}$ En Alemania el control de constitucionalidad de una norma de rango legal con efecto general puede de ser planteado por el Canciller con el apoyo de su gabinete, un tercio del Bundestag o el gobierno de un Land. En España si se trata de un recurso de inconstitucionalidad dirigido contra una ley vigente, los únicos legitimados activos son el presidente del gobierno, el defensor del pueblo, cincuenta diputados o cincuenta senadores, los órganos colegiados ejecutivos y asambleas de las comunidades autónomas.
} 
sesgo político de la mayoría del tribunal, del ordenamiento jurídico y de la propia constitución.

La legitimación activa para activar un proceso de control de constitucionalidad expost de la ley puede otorgarse también al juez ${ }^{26}$. Dada la naturaleza de su competencia no parece plausible otorgarle la facultad de promover el examen de constitucionalidad de normas legales al margen del litigio que conoce y, por lo tanto, su legitimación se circunscribe a las disposiciones susceptibles de ser aplicadas en un proceso ya iniciado. No hay razón para conferir a los jueces la posibilidad de requerir un examen de constitucionalidad de normas cuando éstas no tienen directa relación con el ejercicio concreto de sus competencias ${ }^{27}$.

La oportunidad en que es posible plantear la cuestión de constitucionalidad no depende de una decisión del juez, al menos en teoría. Más bien, el ejercicio de esta facultad por el juez dependerá de la existencia de un proceso que conoce y de una norma aplicable a su resolución que aparenta adolecer de un vicio de constitucionalidad. No hay en la gestación del control sintonía con las necesidades o demandas del sistema político, pese a que el funcionamiento de éste puede verse afectado de manera significativa por la invalidación de un precepto legal considerado inconstitucional.

Un tercer posible legitimado para impetrar el examen de constitucionalidad de una norma legal es la parte litigante afectada por la aplicación de una norma cuyo contenido aparece como contrario a la constitución. Los intereses que dan origen al litigio pueden justificar de manera suficiente la necesidad de un examen de constitucionalidad de las normas llamadas a resolverlo. En principio, este legitimado persigue la satisfacción del interés privado que impulsa el litigio y, por lo mismo, tampoco promueve el examen

${ }^{26}$ El artículo 61-1 de la Constitución francesa permite que el Consejo de Estado o la Corte de Casación remitan al Consejo Constitucional una disposición legal que se cuestiona por infringir los derechos y libertades garantizados por la Constitución en un proceso en curso. En Italia el artículo 1 de la Ley constitucional de 9 de febrero de 1948, dispone que la cuestión de legitimidad constitucional de una ley o acto con fuerza de ley puede ser planteada ante la Corte Constitucional de oficio por el juez o por una de las partes en el curso de un juicio (en tanto no sea retenida por el juez por manifiestamente infundada). En determinadas materias las regiones italianas también pueden suscitar cuestión de constitucionalidad. En España, la cuestión de inconstitucionalidad es planteada por un órgano judicial que considera que, en un proceso que conoce, puede aplicarse una norma con rango de ley de cuya validez depende el fallo y que puede ser contraria a la Constitución.

${ }^{27}$ Cabe notar que una facultad independiente del proceso podría afectar la valoración pública de la neutralidad partidista del juez, toda vez que sus requerimientos podrían develar afinidades o prejuicios de carácter político coincidentes con los sostenidos por los representantes populares. 
de constitucionalidad en sintonía con los requerimientos del sistema político. Sin embargo, el ejercicio de su acción podría relacionarse con intereses de carácter político en al menos dos situaciones. La primera es la resistencia a la aplicación de una nueva ley o norma y que cuenta con el apoyo de un argumento constitucional. La segunda es la búsqueda de una situación de hecho que permita generar los elementos que sustentan la acción. En ambos casos, un grupo o minoría accede al control de constitucionalidad buscando una consecuencia de carácter general, aun cuando ésta no derive de la configuración formal del mecanismo de control.

A las opciones anteriores puede sumarse una legitimación sin restricciones, que permita a cualquier ciudadano cuestionar la constitucionalidad de una disposición legal vigente. Una acción popular en esta materia podría generar una actividad difícil de encausar, dotada de una manifiesta aptitud para modificar el orden jurídico vigente, pero sin capacidad para sustituirlo por uno nuevo (al menos mediante la instancia jurisdiccional).

En las dos últimas opciones de legitimación activa comentadas, la del juez y la de la parte litigante, es claro que el control nace como un examen de tipo concreto, asociado a un caso o litigio en el cual es pertinente aplicar una disposición legal aparentemente contraria a la constitución. El proceso y su resultado, sin embargo, tienden a alejarse de los resultados propios de un control de tipo concreto. Esto explica que en España la doctrina haya caracterizado el control de constitucionalidad que nace de una cuestión planteada por el juez como un control concreto impropio. En el régimen español, aunque del caso depende el inicio de proceso de revisión constitucional, éste no puede extenderse al examen de su presupuestos, su legalidad o cuestiones de carácter subjetivo ${ }^{28}$. El propio Tribunal Constitucional español sostiene que tanto el recurso abstracto como la cuestión de inconstitucionalidad tienen una identidad teleológica "que se traduce, en ambos supuestos, en un control abstracto de la constitucionalidad, en que el análisis, ajeno a la consideración subjetiva se concentra en la pura y sola confrontación de la ley cuestionada con el precepto constitucional pretendidamente infringido. (...) sin tomar en consideración, salvo en lo relativo a la viabilidad de la cuestión, las concretas circunstancias del supuesto planteado en el proceso del que aquélla deriva, sobre las que nada podemos deciry que en nada, tampoco, han de condicionar nuestro enjuiciamiento"29. La cuestión de inconstitucionalidad española, planteada por el juez, se suscita como un control concreto asociado a un proceso, pero en su tramitación pierde parte de esta nota y culmina, en su sentencia, fun-

\footnotetext{
${ }^{28}$ CaAmaño Domínguez, Francisco, cit. (n. 2), p. 52.

${ }^{29}$ Sentencia del Tribunal Constitucional español N ${ }^{\circ} 238 / 1992$.
} 
cionando como un control de naturaleza abstracta ${ }^{30}$. Conviene no perder de vista este análisis doctrinal para aproximarse al número 6 del artículo 93 de la Constitución chilena.

\section{El CARÁCTER CONCRETO DEL CONTROL DE INAPLICABILIDAD} POR INCONSTITUCIONALIDAD PREVISTO EN EL ARTÍCULO $93 \mathrm{~N}^{\circ} 6 \mathrm{DE}$ La Constitución CHILENa

La acción de inaplicabilidad prevista en el número 6 del artículo 93 C.Pol. tiene un inicio propio de control concreto, pues su admisión a trámite depende de la existencia de un juicio pendiente en el que podría aplicarse la norma legal cuestionada. Asimismo, el término del proceso tiene efectos declarados por la Constitución típicos del modelo de control concreto. No obstante lo anterior, en la regulación del proceso pueden identificarse también elementos que pertenecen más bien a un modelo de control abstracto. Una mirada general a las consecuencias del control de inaplicabilidad sugiere que la explicación que ofrece el modelo concreto es, al menos, insuficiente.

Hay aspectos del control de constitucionalidad ejercido mediante el recurso de inaplicabilidad que no ofrecen duda en su carácter de control concreto. Así, es claro que el control de la acción de inaplicabilidad tiene un carácter concreto en tanto no sólo se requiere una norma legal que colisione con la Constitución, sino que ella admita una interpretación aplicable en el litigio a quo también contraria a la Constitución ${ }^{31}$. En este sentido, el cuestionamiento de constitucionalidad no es posible si no se ajusta al conflicto y a las normas llamadas a resolverlo. Cabe notar que la inconstitucionalidad declarada se extiende un poco más allá de lo que el litigio necesita, pues no se limita a proscribir una interpretación determinada de la norma, sino a sustraer el precepto completo del proceso, impidiendo su aplicación ${ }^{32}$.

Pero hay otros elementos del proceso de control de constitucionalidad nacido al amparo del número 6 del artículo 93 que cuesta aproximar al modelo concreto. El propio Tribunal Constitucional ha intentado explicar

${ }^{30}$ CaAmaño Domínguez, Francisco, cit. (n. 2), p. 52.

${ }^{31}$ Gómez Bernales, Gastón, La reforma constitucional a la jurisdicción constitucional, en Zúñiga Urbina, Francisco, Reforma constitucional (Santiago, LexisNexis, 2005), p. 677, entiende que si bien la declaración de inaplicabilidad afecta el enunciado formal de la norma legal, la inconstitucionalidad proviene de la interpretación o significado posible de dicho enunciado.

${ }^{32}$ Como el propio Tribunal Constitucional ha indicado, su deber es "evitar que el precepto legal impugnado se interprete y aplique de un modo en que efectivamente produzca un efecto contrario a la Constitución" (sentencias del tribunal constitucional $\mathrm{N}^{\circ}$ 806/07 y $\mathrm{N}^{\circ}$ 993/08). En rigor, sólo la interpretación inconstitucional es la que debiera precaverse. 
la naturaleza especial de la inaplicabilidad, dejando de manifiesto la imposibilidad de adscribirla por completo a uno u otro modelo. Por un lado, ha sostenido reiteradamente que el recurso de inaplicabilidad existente con anterioridad a la reforma del año 2005 "exigia una confrontación directa entre la norma legal y la disposición constitucional” y que la nueva labor de la magistratura constitucional "constitucional no está compelida a la mera comparación abstracta de dos normas de diverso rango, para desentrañar su incompatibilidad"33. La institución de control de inaplicabilidad anterior era "más bien abstracta" en tanto la posterior a la reforma "relativiza el examen abstracto de constitucionalidad", permitiendo que una misma norma sea según el caso concreto, declarada constitucional o inconstitucional ${ }^{34}$.

Estas declaraciones, que sugieren un control de tipo concreto, resultan matizadas con afirmaciones tales como que la inconstitucionalidad "en algunas situaciones puede brotar con claridad del sólo texto del precepto legal cuestionado y, en otras, emergerá de las peculiaridades de su aplicación al caso concreto" 35 . Puede inferirse que si la inconstitucionalidad "brota con claridad del sólo texto del precepto", el Tribunal Constitucional debiera declararla inaplicable en todos los casos que se le planteen y esto es una especie de criterio abstracto ${ }^{36}$.

El carácter concreto, entendido como la relevancia del litigio a resolver, reaparece en el criterio del Tribunal Constitucional según el cual debe evi-

${ }^{33}$ Véanse, entre otras, las sentencia del tribunal constitucional números 473/07, 478/06, 517/07, 529/06, 533/06, 535/07, 546/06 y 1130/08. Como lo ha planteado en otros casos: "la actual formulación de la acción se refiere a la confrontación con la Constitución de la aplicación de la norma y no de ésta en su manifestación abstracta" (sentencia del tribunal constitucional $\mathrm{N}^{\circ} 1011 / 08$ ). Agrega que "no implica, necesariamente, una contradicción abstracta y universal con la preceptiva constitucional" (sentencia del tribunal constitucional $\left.\mathrm{N}^{\circ} 1038 / 08\right)$.

${ }^{34}$ Sentencias del tribunal constitucional números 536/07, 596/06, 741/07 y 755/07 y 970/08. El Tribunal Constitucional agrega: "las características y circunstancias particulares y precisas del caso concreto de que se trate han adquirido, en el actual texto constitucional, una relevancia sustancialmente mayor a la que debia atribuirseles antes de 2005 pues, ahora, la decisión jurisdiccional de esta Magistratura ha de recaer en la conformidad o contrariedad con la Constitución que la aplicación del precepto impugnado pueda tener en cada caso concreto sub lite" (sentencias del tribunal constitucional núme$\operatorname{ros} 755 / 07,791 / 07$ y 1065/08). En otro caso y citando a Francisco Vega y Francisco Zúñiga, el Tribunal Constitucional nota que su labor "deberá prestar especial atención al mérito del proceso al interior del cual dicha norma legal impugnada podrá ser eventualmente aplicada" (sentencia del tribunal constitucional $N^{\circ}$ 967/07).

${ }^{35}$ Sentencias del tribunal constitucional $N^{\circ} 810 / 07$ y N $970 / 08$.

${ }^{36}$ Por otro lado el Tribunal Constitucional ha declarado que " no cabe la inaplicabilidad respecto de impugnaciones genéricas y abstractas" (sentencias del tribunal constitucional $\mathrm{N}^{\circ} 495 / 06 \mathrm{y} \mathrm{N}^{\circ} 523 / 06$ ). 
tarse una declaración de inaplicabilidad cuando "pudiera producir una lesión de mayor envergadura constitucional que aquella que se pretende remediar" ${ }^{\prime 3}$. Esta mirada se reafirma cuando el Tribunal Constitucional ha reconocido el ámbito que le es extraño, como es el de los conflictos de legalidad radicados en el proceso $a q u o^{38}$. No es función del Tribunal Constitucional aclarar el sentido que tienen determinados preceptos legales, dado que esto es una cuestión de legalidad cuya resolución es propia de los jueces de fondo ${ }^{39}$.

El análisis que realiza el Tribunal Constitucional en el control de inaplicabilidad, al dirigirse al efecto concreto producido en el proceso, debiera prescindir de la mirada más amplia que exige el control de tipo abstracto del artículo 93 número $7^{\circ} \mathrm{CPol}$. Por tal motivo, su única guía en la evaluación de la interpretación del precepto legal cuestionado ha de ser que ésta sea aplicable a las circunstancias del caso que sustenta el recurso de inaplicabilidad. No hay razón para pedir al Tribunal Constitucional que busque una interpretación de la norma impugnada acorde con la Carta Fundamental, como sí la hay en el control abstracto propio de la declaración de inconstitucionalidad ${ }^{40}$. Buscar en la inaplicabilidad una interpretación de la ley conforme con la Constitución induce a pensar en que estamos ante un control de tipo abstracto, pues ante un efecto derogatorio tiene sentido buscar la compatibilidad entre lo planteado por el legislador-representante del soberano y lo dispuesto por el mandato constitucional. Sin embargo, el Tribunal ha dicho en un fallo recaído en un recurso de inaplicabilidad "que el juez constitucional debe, para la plena vigencia normativa de la Constitución, buscar una interpretación de la ley que se acomode a sus valores, principios y finalidades, en un parámetro de razonabilidad"41.

Por último, conviene notar que el principal factor que merma el carácter concreto del control de constitucionalidad originado en el recurso de inaplicabilidad es su radicación en un único tribunal, que resuelve en pleno. Así, si bien la inaplicabilidad es declarada en un proceso y sólo sustrae la norma de litigio correspondiente, lo cierto es que toda parte de un proceso que pueda resultar beneficiada por la no aplicación del precepto accionará ante el

\footnotetext{
${ }^{37}$ Sentencia del tribunal constitucional $\mathrm{N}^{\circ} 821 / 07$.

${ }^{38}$ Como por ejemplo, la cuestión de determinación de la ley decisoria de la litis y de su vigencia en el tiempo.

${ }^{39}$ Sentencias del tribunal constitucional $\mathrm{N}^{\circ} 522 / 06$ y $\mathrm{N}^{\circ} 1214 / 08$.

${ }^{40}$ Según el Tribunal Constitucional, en sede de inconstitucionalidad debe "buscar, al menos, alguna interpretación del precepto cuestionado que permita armonizarlo con la Carta Fundamental y sólo en el evento de no ser ello posible, unido a la necesidad de cautelar integralmente la plena vigencia de los principios de supremacia constitucional, igualdad ante la ley y certeza jurídica, resultará procedente y necesaria la declaración de inconstitucionalidad" (Sentencia del tribunal constitucional $N^{\circ} 558 / 07$ ).

${ }^{41}$ Sentencia del tribunal constitucional $\mathrm{N}^{\circ} 791 / 07$.
} 
Tribunal Constitucional, con una buena probabilidad de obtener el mismo resultado si los supuestos del efecto inconstitucional son los mismos. En el caso chileno no es raro entonces que la primera declaración de inaplicabilidad acogida desencadene la interposición de numerosos recursos, toda vez que es previsible que el mismo razonamiento que conduce a la inaplicación será sostenido por el mismo tribunal ${ }^{42}$. Como ya señalamos, en el modelo norteamericano de control concreto, la inconstitucionalidad declarada por un tribunal puede afianzarse o debilitarse con fallos posteriores, a menos que se trate de la Corte Suprema federal.

\section{LOS INTERESES DE QUIENES INTERVIENEN \\ EN EL PROCESO CONTROL JURISDICCIONAL}

DE CONSTITUCIONALIDAD DE LA LEY CONCRETO Y "EX POST"

Interés es provecho, utilidad, ganancia. En el ámbito jurídico también es un título o expectativa fundada en un derecho subjetivo. El primer sentido nos ayuda en nuestro análisis; el segundo introduce un elemento jurídico que nos aleja de la cuestión tratada. Los intereses-utilidad presentes en un proceso son numerosos y distintos (jurídicos, políticos, sociales, económicos, psicológicos, etc.), pero conforman un conjunto coherente para cada uno de los que intervienen en él.

En un proceso privado clásico la existencia y jerarquía de los intereses concurrentes es reconocida por el ordenamiento jurídico. El juez y los terceros que intervienen en el proceso no ponen en cuestión la primacía del conflicto delimitado por las partes, conforme con sus intereses, como núcleo de la respuesta estatal que se pretende obtener ${ }^{43}$. Por consiguiente, en un proceso de este tipo no debieran generarse fuerzas o tensiones que desvíen el curso del asunto hacia ámbitos fuera de los intereses de los litigantes.

A este respecto, la situación del litigio en que, de manera incidental, se cuestiona la constitucionalidad de una norma jurídica es por completo distinta. El conflicto particular se transforma en el escenario de una con-

${ }^{42} \mathrm{El}$ año 2010, el 61\% de todos los requerimientos de inaplicabilidad interpuestos recayó en la misma norma, el artículo 199 del Decreto con fuerza de ley $\mathrm{N}^{\circ} 1$, de 2005 del Ministerio de Salud (norma de la ley sobre instituciones de salud previsional que permitía a dichas empresas reajustar unilateralmente el precio de los contratos de salud por el simple aumento de la edad o por el sexo de los cotizantes y sus cargas, en base a una tabla de factores de riesgo fijada administrativamente). Los 158 requerimientos señalados constituyeron el $51 \%$ del total de los asuntos ingresados al Tribunal Constitucional. El precepto cuestionado fue declarado inconstitucional en agosto del mismo año.

${ }^{43}$ Según Fiss, Owen M., The Bureaucratization of the Judiciary, en The Yale Law Journal, 92 (julio de 1983) 8, p. 1443, la fuente de la legitimidad judicial es el proceso individualista. Su burocratización tiende a corroerlo. 
tienda entre los defensores de la norma o status quo y quienes propugnan su eliminación, batalla que por los inevitables efectos generales del control de constitucionalidad puede convocar a toda persona u órgano beneficiado o perjudicado por la disposición cuestionada. Unos y otros, desde distintas categorías habilitantes, intentan intervenir en el proceso y obtener un resultado favorable a sus intereses. Como es lógico, este esfuerzo tensiona la estructura de un proceso diseñado para servir, de manera principal y excluyente, los intereses de las partes. A continuación revisaremos de manera sucinta la posición de quienes defienden distintos intereses en el proceso de control de constitucionalidad.

Como se señaló arriba, en el ejercicio del control jurisdiccional de constitucionalidad de carácter concreto el punto inicial es un litigio entre particulares. En el ordenamiento jurídico chileno, se otorga a las partes de un proceso la posibilidad de interponer un recurso de inaplicabilidad por inconstitucionalidad, en tanto se cumpla con los requisitos del artículo 93 CPol. Desde un punto de vista subjetivo, el recurso de inaplicabilidad por inconstitucionalidad se suma al conjunto de instrumentos que el proceso otorga a las partes para encausar y resolver su conflicto. En tal sentido, su interposición dependerá de su potencial contribución al resultado perseguido por los litigantes. Entonces existen al menos dos intereses o conjunto de intereses, los de demandante y demandado, que pretenden el reconocimiento del tribunal como derecho subjetivo o interés protegido por el ordenamiento jurídico. Las instituciones del proceso privado se han construido precisamente en función de este conjunto de intereses.

El interés público u objetivo de asegurar la supremacía de la Constitución no forma parte de los intereses de las partes, al menos en el nacimiento del litigio. Por lo mismo, el impacto general de la sentencia que resuelve el recurso y su incidencia en la supremacía de la Constitución, no forma parte de la esfera de intereses de los litigantes. Vistas así las cosas, es posible que la parte que interpone un recurso de inaplicabilidad genere la posibilidad de una reforma legal (derogatoria) sin la intención de conseguirla, esto es, sin el propósito de propiciar un efecto general. Por ejemplo, si una parte interpone un recurso de inaplicabilidad por inconstitucionalidad contra el artículo 2331 CC., es claro que su interés es obtener una indemnización pecuniaria para compensar el daño causado por expresiones injuriosas proferidas en su contra ${ }^{44}$. No hay

\footnotetext{
${ }^{44}$ Nos referimos a la sentencia del Tribunal Constitucional $N^{\circ} 1679 / 10$, en la cual acoge la pretensión de un conocido animador de espectáculos que cuestiona el mencionado artículo del Código Civil. Este artículo señala que "las imputaciones injuriosas contra el honor o el crédito de una persona no dan derecho para demandar una indemnización pecuniaria, a menos de probarse daño emergente o lucro cesante, que pueda apreciarse en dinero; pero ni aun entonces tendrá lugar la indemnización pecuniaria, si se probare
} 
razones para suponer que dicho recurso persigue un interés más general, como por ejemplo, modificar el ordenamiento legal para restringir el ejercicio de la libertad de informar u opinar conforme con la Constitución. El interés de la parte, dado el potencial efecto general del fallo del Tribunal Constitucional, resulta satisfecho junto con un interés de carácter general cuyo apoyo social y político no es posible dimensionar.

Por cierto que es admisible partir de un supuesto distinto. En algunos litigios concretos que dan sustento a un recurso de inaplicabilidad, es posible intuir que el proceso es sólo un instrumento para lograr un objetivo legislativo: la derogación de una disposición de rango legal ${ }^{45}$. Con esta mirada, observamos que el ordenamiento fundamental ofrece a cualquier persona o grupo de personas la posibilidad de impulsar la derogación de una norma legal, sin otra exigencia que la existencia de un proceso pendiente y de un argumento que permita cuestionar la constitucionalidad del precepto aplicable al litigio. En contraste con esta vía para modificar el ordenamiento vigente, cualquier individuo o grupo que busca una reforma legal debiese utilizar los canales tradicionales de la democracia y promover una acción por parte de los representantes populares. El camino político tradicional, por supuesto, no es sencillo y de ordinario exige transar con todos los intereses que conforman la mayoría parlamentaria. En rigor, el litigante que busca un cambio en el ordenamiento jurídico convierte en instrumentos el proceso inicial y el del control de constitucionalidad y, por lo mismo, tanto la justificación formal y sustantiva de la acción individual, como el conocimiento y decisión jurisdiccional resultan sobrepasadas por un interés ajeno a la naturaleza del proceso.

En el derecho chileno y en el derecho comparado, el cuestionamiento de constitucionalidad de una norma legal vigente también concierne a los titulares del poder político. Es por ello que en distintos sistemas de control jurisdiccional de constitucionalidad se acoge la necesidad de informarles del proceso ya iniciado, para permitir su participación en él. Para el régimen constitucional, tanto el gobierno como el poder legislativo encarnan el interés estatal actual y éste, prima facie en una democracia, debiera dirigirse a la defensa de un acto que se entiende actualización de la voluntad popular a través de sus representantes acorde con la Constitución ${ }^{46}$.

la verdad de la imputación". El daño moral de la injuria no genera, entonces, derecho a indemnización civil.

${ }^{45} \mathrm{La}$ acción de protección ofrece una buena alternativa para generar un proceso que permite cuestionar la constitucionalidad de un precepto determinado.

${ }^{46}$ Aunque pueden existir razones políticas que expliquen una actuación del gobierno o del legislativo en el sentido contrario -esto es, apoyando la declaración de inconstitucionalidad- es difícil aceptarlas considerando el conjunto de medios políticos 
La invitación a intervenir en el proceso puede realizarse a distintos órganos del Estado. Bien puede convocar a todos los órganos co-legisladores o bien sólo a aquellos que tienen una competencia técnica apta para la defensa del ordenamiento legal existente. En Chile, el artículo 86 de la Ley orgánica constitucional del Tribunal Constitucional (= LOCTC.) señala que una vez declarado admisible el requerimiento de inaplicabilidad de un precepto legal corresponde ponerlo en conocimiento de la Cámara de Diputados, Senado y Presidente de la República, órganos que pueden formular observaciones y presentar antecedentes dentro del plazo de veinte días. En los Estados Unidos, la sección 2403 del Código Judicial federal señala que en toda acción, demanda o procedimiento en que el estado federal no es parte y se cuestiona la constitucionalidad de una ley federal que afecta el interés público, el tribunal debe certificar tal hecho y comunicarlo al procurador general para permitir la presentación de evidencia o argumentación sobre la cuestión de constitucionalidad ${ }^{47}$.

Si la convocatoria es a un órgano más bien técnico, la defensa de la constitucionalidad de la norma estará menos condicionada por un juicio de carácter político. Esto porque en términos prácticos, los titulares de los principales órganos del poder político (presidente, mayoría parlamentaria), tendrán un mayor o menor interés en la defensa del status quo normativo que es objeto de cuestionamiento de constitucionalidad. Tendrán mayor interés y procurarán una adecuada defensa jurídica y política de la norma en aquellos casos que la regla existente se acomode a su ideario político o, aunque críticos de ella, no consideren viable generar el consenso político para su reemplazo. Tendrán menor interés en la defensa de la norma en aquel caso en que ella haya perdido el sustento político que le dio origen, no se considere inconveniente su eliminación del ordenamiento jurídico o parezca viable impulsar un nuevo consenso para elaborar la norma de reemplazo.

Un tercer grupo que interviene en el proceso de control de constitucionalidad son los jueces. A su respecto, una primera cuestión que debe subrayarse es que el ejercicio de la competencia de control por parte de los jueces constitucionales no es equiparable a la labor que realizan los jueces ordinarios. El juez ordinario tiene como principal labor buscar la solución justa del conflicto conocido mediante la aplicación del derecho a los hechos probados. El Estado tiene un interés en la provisión de órganos jurisdicciona-

y jurídicos disponibles para modificar la disposición cuestionada. Por ello, es probable que una voluntad de este tipo se encubra y más bien se manifieste en pasividad en el proceso de control o una débil defensa de la norma.

${ }^{47}$ Nótese que se trata de una ley federal que afecta un interés público. Esta referencia se explica por la existencia de leyes particulares y sirve para justificar la intervención de los defensores de dicho interés. 
les para la solución de conflictos entre particulares pues la justicia es un pilar de la paz social, condición esencial para la subsistencia del orden político ${ }^{48}$. La paz de la comunidad política depende de la labor de este tercero imparcial que resuelve los conflictos entre particulares impartiendo justicia.

La labor del juez constitucional en el proceso de control de constitucionalidad de carácter concreto es distinta, pues tiene que velar por la supremacía constitucional por sobre toda otra consideración. Este asegurar la vigencia efectiva de la norma fundamental no tiene relación con la justicia del caso. El caso es instrumental para el control de constitucionalidad y, de hecho, la declaración de inaplicabilidad por inconstitucionalidad permite iniciar una acción conforme con el artículo 93 número $7^{\circ}$, en cuyo conocimiento el juez constitucional tiene el deber de buscar una interpretación conforme con la Constitución $n^{49}$. Cabe pensar que los argumentos entregados por el Tribunal Constitucional para autoimponerse el deber de buscar la interpretación ajustada a la Constitución contamina o influencia el juzgamiento en el proceso que sirve de base a la derogación de la disposición.

El interés de la supremacía de la Constitución cubre numerosas interpretaciones de los contenidos de la Carta Fundamental y suele otorgar al juez constitucional una herramienta flexible para servir otros intereses. Así, constreñir o expandir la función social del Estado, las libertades políticas o la protección de la garantía de propiedad pueden ser objetivos políticos perseguidos desde la jurisdicción constitucional.

${ }^{48}$ Carré de Malberg, R., Teoría general del Estado (México, Fondo de Cultura Económica, 2000), p. 250, entiende que el Estado "tiene por misión, en el interior, asegurar el orden y el derecho en las relaciones que entre sí mantienen los individuos”; y que las funciones estatales se reducen a tres clases de actividad: la legislación, la administración y la justicia. Para Jellinek, Georg, Teoría general del Estado (México, Fondo de Cultura Económica, 2000), p. 540, las funciones obedecen a los fines y dentro de estos se encuentra la creación y mantenimiento del derecho. Este fin exige un mecanismo que permita fijar jurisdiccionalmente un derecho dudoso o discutido. La jurisdicción fija en los casos individuales el derecho incierto o cuestionable o las situaciones e intereses jurídicos.

${ }^{49} \mathrm{El}$ interés democrático justifica reservar la declaración de inconstitucional para casos en que no sea posible ninguna interpretación acorde con la Constitución: "En todo caso, es indiscutible que dicha declaración constituye el último recurso para asegurar la supremacía constitucional, desde que implica no sólo la anulación o derogación de un acto emanado del órgano legislativo -expresión éste irrecusable de la soberania popular-, sino que conlleva un cierto grado de inseguridad jurídica ante el vacio normativo que se produce por la desaparición de la norma jurídica naturalmente destinada a regular inmediatamente las conductas, cuyo reemplazo es incierto" (sentencia del Tribunal Constitucional $\mathrm{N}^{\circ} 558 / 06$ ). 


\section{LAS CARACTERÍSTICAS DEL PROCESO CIVIL O PRIVADO} Y EL PROCESO DE INAPLICABILIDAD POR INCONSTITUCIONALIDAD

El proceso civil se identifica por su carácter bipolar, relativo, retrospectivo, la interdependencia entre el derecho o interés alegado y el remedio pretendido, y su inicio y control sometido a las partes ${ }^{50}$. El proceso civil es bipolar, en el sentido que la litigación se estructura como una competencia entre dos individuos o intereses unitarios opuestos diametralmente, a ser resuelto con un principio de suma cero. El proceso tiene efectos relativos ya que el efecto de la sentencia está confinado a las partes y la relación de éstas con el tribunal culmina con la sentencia que pone término al litigio.

La litigación es retrospectiva pues la controversia tiene como base un conjunto identificado de hechos que pueden o no haber ocurrido y que, si sucedieron, tienen incidencia en las relaciones jurídicas de las partes en conflicto. Conviene notar que la decisión de litigar tiene como insumo básico las pruebas con que se puede contar para acreditar los hechos pertinentes.

El ámbito de la adjudicación a una de las partes constituye, en mayor o menor medida, una compensación por la vulneración o menoscabo de un derecho o interés protegido por el ordenamiento jurídico. La extensión de este ámbito también es una variable fundamental en la decisión de litigar (o negociar en pos de un acuerdo).

El proceso privado nace y se estructura con las pretensiones formuladas por las partes. La tarea de identificar hechos y derechos disputados es de ellas y el juez es el arbitro neutral de sus interacciones en el proceso. A éste sólo le corresponde resolver las cuestiones de derecho que son debidamente planteadas por los litigantes.

Aunque es probable que el modelo puro de proceso privado no exista en ningún ordenamiento jurídico, es claro que los elementos que lo configuran han inspirado el diseño de las reglas procedimentales que lo rigen.

Desde un punto de vista material, la interposición de un recurso de inaplicabilidad por inconstitucionalidad inicia un nuevo proceso ante un nuevo tribunal. En este nuevo proceso se aplican disposiciones procedimentales típicas de la litigación privada, las que sin duda tienen incidencia en su resultado final. Esta incidencia puede ser criticada cuando distorsiona una respuesta que ha de afectar a todo el ordenamiento jurídico.

\section{Carácter bipolar de la litigación privada.}

Como ya indicamos, el proceso civil es bipolar, ya que la litigación se

\footnotetext{
${ }^{50}$ Chayes, Abram, The Role of the Judge in Public Law Litigation, en Harvard Law Review, 89 (mayo, 1976) 7, p. 1282.
} 
estructura como una competencia entre dos individuos o intereses unitarios opuestos y que debe ser resuelto con una adjudicación que tiende a un efecto de suma cero. En el contexto de un proceso bipolar, el juez debe admitir las pretensiones de las partes que tienen un interés justiciable y escuchar a todos los afectados por el proceso, esto es, a todos quienes tienen un interés en él ${ }^{51}$. Quienes tienen un interés en algún aspecto del resultado del proceso privado en curso, pueden integrarse al mismo con un estatuto jurídico procedimental especial. Los terceros, ajenos a la relación jurídica que sustenta el proceso, tienen un interés reconocido por la legislación que no incide en el núcleo del conflicto que se pretende resolver.

En el proceso de inaplicabilidad la bipolaridad es afectada por las disposiciones de la Ley Orgánica Constitucional del Tribunal Constitucional que reconocen a los órganos constitucionales interesados la posibilidad de "ser tenidos como parte" 52 . En consecuencia, la Cámara de Diputados, el Senado o el presidente de la República pueden actuar en el proceso como partes, sumando argumentos e intereses que no necesariamente forman parte de las cuestiones generadas por los litigantes originales. El Tribunal Constitucional puede acoger los planteamientos de los órganos constitucionales interesados que se han constituido como partes, de manera ordinaria y sin la exigencia de razones fundadas. Los tres órganos políticos están legitimados entonces para intervenir en el centro de la discusión planteada por las partes, introduciendo nuevos argumentos funcionales a sus propios intereses e incidiendo en el resultado final del requerimiento de inaplicabilidad. Es más, en aras de la supremacía de la Constitución el legislador permite al propio Tribunal añadir fundamentos distintos a los invocados por las partes en la litis "excepcionalmente y por razones fundadas", adición que también puede tener incidencia en el resultado del recurso sin relación a los argumentos expuestos por las partes ${ }^{53}$.

Con todo, podría argüirse que el carácter bipolar está protegido por

${ }^{51}$ Fiss, Owen M., cit. (n. 39), p. 1452.

${ }^{52}$ Artículo 44 LOCTC. Los órganos constitucionales interesados son aquellos que de conformidad con dicha ley "pueden intervenir en cada una de las cuestiones que se promuevan ante el Tribunal, sea en defensa del ejercicio de sus potestades, sea en defensa del orden jurídico vigente" (artículo 44, inciso 2). La expresión de la voluntad del órgano constitucional interesado debe realizarse dentro del plazo que la ley otorga para formular observaciones y presentar antecedentes. Según el artículo 86 de la misma ley, la Cámara de Diputados, el Senado y el presidente de la República pueden formular observaciones y presentar antecedentes dentro del plazo de veinte días contados desde que se haya dado cuenta en sala de la admisión del recurso de inaplicabilidad en el caso de cada una de las cámaras o desde su ingreso a la oficina de partes del Ministerio Secretaría General de la Presidencia en el caso del presidente de la República.

${ }^{53}$ Artículo 88 LOCTC. 
cuanto todos los llamados a intervenir en el proceso han de apoyar a una u otra parte, esto es, a la parte que requiere la inaplicabilidad por inconstitucionalidad o bien a la parte que sostiene la constitucionalidad de la norma cuestionada. En efecto, en este sentido la bipolaridad no resulta afectada, pues hay un cierto alineamiento con el interés principal de cada litigante. Sin embargo, norma objeto del litigio convoca a los interesados al margen del conflicto suscitado entre las partes litigantes y fuerza su participación en la tramitación de la inaplicabilidad en pos de unos objetivos que pueden exceder los delimitados en el proceso original. Entre otras cosas, esta intervención de nuevos litigantes puede modificar de manera radical los medios y la asistencia letrada disponibles para servir las posiciones de cada parte. En un proceso privado bipolar tradicional uno de los elementos que condiciona la decisión de litigar es, precisamente, la capacidad de defensa jurídica con que cuenta cada parte.

Puede concluirse, entonces, que el carácter bipolar en un proceso concreto de control de constitucionalidad se abre a un conjunto de intereses y personas que resultan afectados por el cuestionamiento de una norma legal vigente. Estos exceden las circunstancias y efectos del caso concreto, y por lo mismo las figuras tradicionales del proceso civil no se ajustan bien del todo a su realidad y necesidades.

\section{Efecto relativo.}

El efecto relativo de la sentencia de inaplicabilidad es ordenado por la propia Constitución. El número $6^{\circ} \mathrm{del}$ artículo $93 \mathrm{CPol}$. encarga al Tribunal Constitucional resolver "la inaplicabilidad de un precepto legal cuy a aplicación en cualquier gestión que se siga ante un tribunal ordinario o especial (...)" y por lo mismo, la sentencia de inaplicabilidad la declara para "la gestión que se siga" y no para otro trámite o proceso. La Constitución ofrece la inaplicabilidad como remedio a un efecto inconstitucional dentro del proceso derivado de la potencial aplicación de un precepto "que pueda resultar decisivo en la resolución" del asunto ${ }^{54}$.

La Carta Fundamental dirige el control de constitucional concreto ex post hacia una consecuencia confinada al proceso en que se suscita. Sin embargo, hay factores tienden a extender el juicio de constitucionalidad que nace del requerimiento de inaplicabilidad a otras personas que no forman parte del proceso. El primer factor relevante es que la inconstitucionalidad puede derivar más de la norma que de su aplicación al caso concreto: "la inconstitucionalidad en la aplicación de un precepto puede derivar esencialmente de dos circunstancias. La primera es la inconstitucionalidad intrinseca de la

\footnotetext{
${ }^{54}$ Artículo 93 inciso $11^{\circ} \mathrm{CPol}$.
} 
norma, que, compulsada con el texto constitucional, no admite conciliación y, por tanto, generalmente se traducirá en su aplicación contraria al mismo. La otra se expresa a través de una disposición que, en abstracto, es compatible con la Constitución, pero que, aplicada a una relación jurídica singular y concreta, provoca efectos contradictorios con ella. Esta nota, proveniente de la generalidad de la norma-que no subsume necesariamente todas las situaciones que se dan en la realidad-, es la que genera la contrariedad especifica en la aplicación" (sentencia del Tribunal Constitucional $N^{\circ} 1038 / 08$ ). Si la inconstitucionalidad es "intrinseca" de la norma, quienes resultan perjudicados por su aplicación y son partes en un proceso, formularán un requerimiento de inaplicabilidad con una alta probabilidad de obtener la declaración de inaplicabilidad. Esta situación no debe asimilarse a la predictibilidad que puede generar todo precedente, ya que en este caso el propio Tribunal está afirmando que las circunstancias del caso no tienen especial incidencia en el juicio de inconstitucionalidad ${ }^{55}$. El reiterado cuestionamiento de constitucionalidad de algunos preceptos ante el Tribunal Constitucional sugiere que la parte litigante asume la probabilidad de obtener un resultado favorable a sus intereses a partir de una declaración de inaplicabilidad inicial ${ }^{56}$.

La declaración de inaplicabilidad es formulada por el pleno del Tribunal Constitucional, con lo cual el criterio de interpretación de la Constitución que lo sustenta tiene un horizonte de vida que al menos alcanza a la siguiente renovación de sus integrantes. Desde un punto de vista interno, el precedente es fundamental para la formación y sustentación de los consensos dentro del

55 Autores como Aldunate Lizana, Eduardo, Jurisprudencia constitucional 2006-2008. Estudio selectivo (Santiago, LegalPublishing, 2009), p. 23, subrayan que en el control concreto de inaplicabilidad, el Tribunal Constitucional ha utilizado argumentación "de carácter absolutamente general y abstracto, no sólo desvinculada del caso y de las pretensiones y alegaciones de las partes, sino que también desvinculada de las propias circunstancias de hecho que se trata de examinar". Este tipo de argumentación da cuenta, entre otras cosas, que la distancia puesta por el constituyente entre el control concreto y abstracto es más una declaración de principios técnicos que una realidad en los criterios del Tribunal.

${ }^{56}$ Ya mencionamos el caso de los artículos 38 ter de la Ley $\mathrm{N}^{\circ} 18.933,199$ del Decreto con fuerza de ley $\mathrm{N}^{\circ} 1$, de 2005 del Ministerio de Salud y 2 de la $\mathrm{N}^{\circ}$ Ley 20.015 el año 2010. Estas disposiciones fueron objeto de 64 recursos de inaplicabilidad el año 2009 , el 26,4\% del total interpuesto ese año (que a su vez constituye el 83,8\% del total de ingresos del Tribunal Constitucional). El año 2009 también se interpusieron 11 recursos contra la segunda frase del inciso primero del artículo del Código Sanitario (que fue declarada inaplicable en la sentencia del Tribunal Constitucional $\mathrm{N}^{\circ} 1253 / 08$ ). Asimismo, el año 2006 se interpusieron más de 80 recursos de inaplicabilidad contra el artículo 116 del Código Tributario (cerca del 40\% del total de requerimientos de inaplicabilidad), que sería declarado inconstitucional en la sentencia del Tribunal Constitucional $\mathrm{N}^{\circ} 681 / 07$. 
Tribunal Constitucional y esencial para el prestigio de la jurisdicción constitucional, por lo que su conservación goza de una posición inicial robustecida en cualquier caso en que claramente sea aplicable ${ }^{57}$. Esta situación afianza la doctrina constitucional construida y por lo mismo asienta la expectativa de futuros litigantes de obtener un resultado sin considerar las circunstancias de su caso. Todo lo anterior propicia el debilitamiento del efecto relativo y es probable que la sentencia de control de constitucionalidad guie el comportamiento de terceros no litigantes de un modo distinto al que deriva de cualquier otra jurisprudencia.

Además, el carácter relativo de la sentencia de inaplicabilidad debe ser confrontado con su función como puerta de entrada a la declaración de inconstitucionalidad de efecto general que puede ser planteada por cualquier persona. Una vez acogido un requerimiento de inaplicabilidad queda franqueado el camino para que mediante una acción pública una norma legal sea derogada por ser contraria a la Constitución. Es difícil sostener que la sentencia de inaplicabilidad que acoge el recurso deducido tiene un efecto relativo cuando ella es la única vía con la cual puede accederse a un control de constitucionalidad que, sin duda es de carácter general, tanto en su legitimación activa como en su efecto en el caso de ser acogido.

\section{Carácter retrospectivo del litigio privado.}

La litigación es retrospectiva pues la controversia se centra en un conjunto identificado de hechos ya acaecidos a los que se pretende aplicar un conjunto de normas existentes con anterioridad a los hechos que dan origen al conflicto sometido a la jurisdicción. El proceso se destina, en parte, a comprobar si los hechos ocurrieron o no y de qué manera, como también a debatir como deben ser interpretadas las normas que pueden aplicarse a su solución. Será el juez en definitiva el que fije los hechos, su incidencia en las relaciones jurídicas de las partes en conflicto y determine la aplicación del Derecho. Notemos que en un litigio privado la decisión de iniciar una acción o no hacerlo tiene como insumo importante las pruebas disponibles para la parte.

El proceso de control de constitucionalidad de carácter concreto se distancia del litigio privado en tanto los hechos y la argumentación sobre la interpretación del conjunto de normas aplicables se mantienen en la esfera del proceso inicial, y el nuevo debate se centra en el ajuste de un precepto potencialmente aplicable a la resolución del conflicto a las normas constitucionales. En el trámite de la inaplicabilidad la argumentación y el razonamiento dejan de mirar hacia el pasado y se concentran en dos cuestiones

${ }^{57}$ Factores que, según ZAGrebeLSKY, Gustavo, cit. (n. 42), pp. 73-77, son conocidos por los jueces constitucionales. 
futuras: el posible efecto inconstitucional de la aplicación de la norma en el proceso y la incidencia de la misma en la resolución del asunto en litigio ${ }^{58}$. La comprobación del hecho sigue siendo un supuesto para la resolución del conflicto entre las partes, pero se agrega un elemento por completo nuevo, ya que el requerimiento de inaplicabilidad genera la posibilidad de modificar las normas aplicables a la resolución del proceso afectando la expectativa de resultado que sustentó la decisión de litigar. El curso de un proceso retrospectivo, con normas definidas de antemano, se encuentra entonces alterado por la necesidad de acreditar un efecto inconstitucional potencial, que no se ha materializado y que podría, o no podría, incidir en la resolución del litigio. En este contexto, la mirada sobre las pruebas disponibles, los hechos y su significado, queda relegada a un segundo plano.

\section{La interdependencia entre el derecho o interés alegado y el remedio pretendido.}

En un litigio privado el ámbito de la adjudicación está delimitado por la compensación debida que surge de la vulneración o menoscabo de un derecho o interés protegido por el ordenamiento jurídico. La extensión de este ámbito es una variable fundamental en la decisión de litigar o buscar otras formas alternativas de resolver el conflicto. La parte litiga sobre la base de un conjunto de normas y pruebas, que le permiten, hasta cierto punto, prever las probabilidades de un resultado favorable o desfavorable.

El proceso de inaplicabilidad conduce a las partes a una respuesta que puede exceder el remedio buscado. En aquellos litigios en que una de las partes defiende una posición jurídica que sostiene también en otros conflictos, el resultado de la inaplicabilidad genera un precedente del que difícilmente podrá escapar. Desde esta perspectiva, la conveniencia de litigar puede diluirse si, como consecuencia de un recurso de inaplicabilidad, se pierde el sustento legal de la posición defendida. En suma, en un proceso de control de constitucionalidad como el comentado, el remedio obtenido puede sobrepasar los derechos o intereses concernidos en el litigio privado original.

\section{Inicio y control sometido a las partes.}

El proceso nace y se construye con las pretensiones de las partes. La responsabilidad por plantear hechos disputados es de ellas y el juez es el arbitro

\footnotetext{
${ }^{58}$ Con todo, como observa Aldunate Lizana, Eduardo, cit. (n. 55), p. 16, los hechos pueden ser relevantes para la determinación del efecto inconstitucional propio de la inaplicabilidad. El Tribunal Constitucional ha sostenido distintos criterios sobre esta cuestión: no le corresponde entrar a ellos pues invadiría las facultades del juez de la instancia; o bien es competente para conocerlos pues son importante para resolver la inaplicabilidad o el efecto inconstitucional.
} 
de sus interacciones en el proceso y que resuelve las cuestiones de derecho que le son debidamente planteadas por los litigantes. En los litigios entre particulares sobre asuntos de derecho privado predominan los intereses de las partes, pues ellas son domini litis, idea que responde a la autonomía personal propia del liberalismo ${ }^{59}$. La autonomía personal de las partes domina la estructura y fines del proceso y por lo mismo ellas lo inician y controlan.

En Chile un segundo legitimado para interponer el recurso de inaplicabilidad es el juez que conoce de la causa en la cual puede aplicarse una norma aparentemente inconstitucional. Como a las partes, se le exige para formular el requerimiento de inaplicabilidad una gestión pendiente ante tribunal ordinario o especial, que la aplicación del precepto legal impugnado pueda resultar decisiva en la resolución del asunto, la presentación de un fundamento razonable y los demás requisitos que establezca la ley.

En el derecho comparado la doctrina pone en duda el carácter de legitimado del juez, pero en Chile es el artículo 79 LOCTC. Mismo el que reconoce como "órgano legitimado" al juez (artículo 79) ${ }^{60}$. El juez puede iniciar un proceso de inaplicabilidad por inconstitucionalidad al margen de las decisiones de las partes. El juez que presenta un requerimiento de inaplicabilidad participa en el proceso ante el Tribunal Constitucional de manera equivalente a una parte ${ }^{61}$. Nuestro legislador no ha establecido en-

${ }^{59}$ Damaska, Mirjan, Las caras de la justicia y el poder del Estado. Análisis comparado del proceso legal (Santiago, Editorial Jurídica de Chile, 2000), p. 164.

${ }^{60} \mathrm{Si}$ bien la doctrina italiana y la alemana utilizan sin cuestionarse la noción de legitimado para referirse al juez, autores como Saavedra Gallo entienden que se trata de un poder-deber. Desde su perspectiva, los órganos judiciales que plantean una cuestión de constitucionalidad no adquieren la condición de partes, pues lo único que varía es que tienen una potestad más. No obstante esta prevención, el Tribunal Constitucional español ha utilizado la voz legitimación para referirse a la situación del juez requirente. TORRes Muro, Ignacio, cit. (n. 14), pp. 100-101.

${ }^{61}$ Así el artículo 80 LOCTC. no distingue entre juez y las partes que interponen un requerimiento y, por tanto, ambos deben exponer "bechos y fundamentos en que se apoya" y "cómo ellos producen como resultado la infracción constitucional". La misma norma exige indicar los vicios de constitucionalidad que se "aducen", por lo que el juez, igual que las partes debe presentar o alegar pruebas, razones, etcétera. Conviene notar que el juez no tiene una oportunidad procesal preestablecida en la cual debe plantear la cuestión de inaplicabilidad, situación que incrementa su ámbito de decisiones con relación al ejercicio del requerimiento. El artículo 82 LOCTC. tampoco diferencia la situación del juez y la parte requirente. Ambos reciben la denominación genérica de "interesados" en su inciso segundo y pueden subsanar defectos de forma u omisión de antecedentes en el plazo de tres días. Del mismo modo, ambos pueden alegar acerca de la admisibilidad del requerimiento. Tanto el juez como la parte pueden solicitar la suspensión del procedimiento (artículo 85). Según el artículo 86 , la admisión del requerimiento puede notificarse al tribunal, otorgándole un plazo de veinte días para formular observaciones 
tonces un estatuto diferenciado entre el juez requirente de inaplicabilidad y la parte requirente de inaplicabilidad, con lo cual se diluye el rasgo distintivo de la litigación privada que comentamos. No obstante lo anterior, la jurisprudencia del Tribunal Constitucional ha sostenido que el interés legítimo que sustenta la acción no es el mismo en el caso de la parte requirente y el juez requirente ${ }^{62}$.

La transformación del juez del litigio en parte distancia de manera ostensible el proceso de inaplicabilidad del modelo de litigación privado. Las consecuencias de este alejamiento pueden dañar el litigio que sustenta el control concreto de constitucionalidad y por ello el Derecho ha desarrollado herramientas o criterios para morigerarlo. En esta línea, es posible observar que en el Derecho comparado se intenta proteger la imparcialidad del juez que recurre al control de constitucionalidad. Así, en el derecho español se ha sostenido que el juez tiene una facultad asociada a un interés, como es conciliar su doble obligación de aplicar la ley y la Constitución y que no admite la inaplicación de la primera por sí mismo ${ }^{63}$. Utilizando su facultad constitucional, el juez puede conocer la aplicabilidad de la norma y respetar la supremacía de la constitucional siguiendo el criterio de la jurisdicción competente. El juez contribuye a la depuración del ordenamiento jurídico planteando una duda razonable acerca de la constitucionalidad de un precepto legal relevante para el proceso que está conociendo. Esta facultad concedida al juez tiene armonía con la conferida a otros órganos y permite promover una cuestión que está vedada a las partes del litigio.

Conviene notar que en el Derecho español el juez no ejerce una acción y no tiene un interés en el resultado del control de constitucionalidad. Tanto el constituyente como el legislador son cuidadosos en este tópico. En este sentido, el artículo 163 de la Constitución española se refiere a la norma con rango de ley que "pueda ser contraria a la Constitución”. Además, el juez no puede escoger la oportunidad procesal en que planteará la cuestión, pues el artículo 35 LOCTC. dispone que la cuestión sólo puede ser planteada "una

y presentar antecedentes. Con todo, el artículo 92 no permite condenar en costas al juez que no haya tenido motivos plausibles para litigar.

${ }^{62}$ Sentencia del Tribunal Constitucional pronunciada en la causa rol No 1029/08. Las partes en el juicio procuran la tutela de un derecho subjetivo o interés protegido. Según el Tribunal Constitucional el juez debe velar por la supremacía de la Constitución dando cumplimiento al mandato del artículo 6 del texto fundamental. En el mismo fallo, nuestro Tribunal Constitucional ha sostenido que la función propia del juez es resolver una contienda entre partes decidiendo de manera imparcial sobre el asunto sometido a su conocimiento.

${ }^{63}$ La idea de la conciliación de la doble obligación del juez puede encontrarse en fallos del Tribunal Supremo (por ejemplo, sentencia pronunciada por la antigua Sala $5^{\text {a }}$ el 17 de diciembre de 1984). 
vez concluso el procedimiento y dentro del plazo para dictar sentencia". Aunque la decisión es del juez, las partes deben ser oídas por el juez que pretende plantear la cuestión de inaplicabilidad. En el derecho español, asimismo, el juez o tribunal que interpone la cuestión de inconstitucionalidad sólo debe indicar la ley o norma con fuerza de ley cuya constitucionalidad se objeta, el precepto constitucional que se supone infringido y justificar en qué medida la decisión del proceso depende de la validez de la norma detectada ${ }^{64}$. Como indican los artículos 36 y 37 Ley Orgánica del Tribunal Constitucional español no corresponde al juez más participación que la ya indicada. Como anota la doctrina, la cuestión opera en su origen como una técnica de control concreto pero ya en su tramitación pierde este carácter (no están legitimadas las partes) y "adquiere, enteramente, en su resolución, las notas del control abstracto" ${ }^{16}$.

En Alemania, autores como Constance Grewe entienden que el poder del juez de acudir al Tribunal Constitucional tiene un carácter subjetivo y objetivo. La cara subjetiva viene dada por la incidencia de la validez constitucional de la norma cuestionada en el resultado del litigio principal y el interés de las partes en una solución rápida. El carácter objetivo ha sido remarcado por la jurisprudencia que tiende a alejarse del asunto inicial y a subrayar la importancia de proteger la autoridad del legislador parlamentario ${ }^{66}$.

Como señalamos antes, la pérdida por las partes litigantes del inicio y control del proceso de inaplicabilidad es una manifestación clara de la ruptura del modelo de litigación privada. La regulación chilena al no promover el distanciamiento del juez del pronunciamiento definitivo de constitucionalidad puede afectar su posición en el proceso pendiente que soporta la inaplicabilidad. El juez chileno debe construir la fundamentación de la inconstitucionalidad y puede participar en el proceso de inaplicabilidad, lo que podría afectar su neutralidad en la interpretación de la norma legal cuestionada en el caso que su requerimiento sea desechado por el Tribunal Constitucional.

${ }^{64}$ El Tribunal Constitucional español ha sostenido que el hecho que sea posible una interpretación de la norma conforme a la Constitución no permite considerar a la cuestión planteada como mal fundada. Según el máximo tribunal, la Constitución no condiciona el planteamiento de la cuestión a la imposibilidad de interpretación conforme con la ley fundamental (sentencia $\mathrm{N}^{\circ} 105 / 1988$ ).

${ }^{65}$ CaAmaño Domínguez, Francisco, cit. (n. 2), p. 52.

${ }^{66}$ Acosta Sánchez, José, Formación de la Constitución y jurisdicción constitucional. Fundamentos de la democracia constitucional (Madrid, Tecnos, 1998), p. 269. También el Tribunal Constitucional español defiende la "dignidad de la ley emanada de la representación popular", para explicar que el juicio adverso del juez no le permite inaplicarla sino sólo cuestionarla ante el Tribunal Constitucional (sentencia $\mathrm{N}^{\circ}$ 17/1981). 


\section{COMEnTARIOS FINALES}

La potencial incidencia del control particular de constitucionalidad en la pervivencia de la norma legal objetada dificulta el predominio de los intereses privados propios del litigio que da sustento al cuestionamiento. En la práctica parece más adecuado concebir el proceso de inaplicabilidad como una especie de litigación pública al servicio del interés de la supremacía de la constitución. Una concepción de este tipo admite el desplazamiento del interés privado de las partes a un segundo plano en aras del propósito de depurar el ordenamiento jurídico de disposiciones que tienen un efecto inconstitucional.

La comprensión de la cuestión de inaplicabilidad como un litigio público en lo que dice relación con la comparecencia de otras personas interesadas permite ofrecer respuestas que el proceso privado tiende a rechazar. En este esquema no es necesario que los interesados en intervenir en una cuestión de inaplicabilidad cuenten con todas las herramientas procesales disponibles para las partes originales del litigio. En el contexto de un litigio público es posible configurar un estatuto de intervención que acoja distintos grados de participación procesal conforme al interés invocado por la persona ajena al proceso ${ }^{67}$. Otro tipo de interesados podría acceder al proceso con un conjunto menor de instrumentos procesales, en tanto sean funcionales a su interés ${ }^{68}$. El propio Tribunal podría invitar a quienes estima importante oír, al modo de las comisiones legislativas de un congreso o parlamento ${ }^{69}$.

${ }^{67} \mathrm{Un}$ interesado como el gobierno federal norteamericano puede, conforme con la sección 2403 (a) del Código Judicial, presentar evidencias y argumentos La presentación de pruebas puede ser relevante para constatar el efecto inconstitucional que fundamenta un requerimiento de inaplicabilidad

${ }^{68}$ En Chile, el Tribunal Constitucional ha aceptado la participación de un tercero que no es parte, como una especie de amicus curiae (sentencia del Tribunal Constitucional N 740/07); véase: Aldunate Lizana, Eduardo, cit. (n. 55), p. 43.

${ }^{69}$ Autores como Shapiro, David L., Some Thoughts on Intervention before Courts, Agencies and Arbitrators, en Harvard Law Review, 81 (febrero de 1968) 4, p. 740, tienen una mirada más restrictiva, pues consideran que la aceptación de un tercero en un litigio sobre la constitucionalidad de una norma debe analizar su posibilidad de acceso a otros remedios -tanto desde un punto de vista legal como práctico- y su potencial contribución al litigio. La decisión que permite su acceso también debiese considerar, según el mismo autor, la evaluación de la inmediatez y daño que puede sufrir como consecuencia de la sentencia del proceso. En la Ley Orgánica del Tribunal Constitucional español se establece el traslado de la cuestión de inconstitucionalidad planteada por el juez a Congreso de los Diputados, Senado, fiscal general del Estado, Gobierno y órganos legislativo y ejecutivo de la comunidad autónoma, en su caso. Todos ellos pueden personarse en el proceso y formular alegaciones sobre la cuestión planteada en el plazo común improrrogable de quince días. 
Desde una mirada externa, asimismo, debe examinarse la ventaja de precaver la litigación múltiple. Es legítimo, además, que la jurisdicción constitucional dimensione ante cada solicitud, el peligro de un número alto de solicitudes de intervención ulterior.

En fin, la comprensión del proceso de inaplicabilidad como proceso debiera tomar una sana distancia del modelo de litigación privada y ajustarse a la función que cumple el control de constitucionalidad en el sistema político democrático contemporáneo.

\section{BIBLIOGRAFÍA}

Acosta Sánchez, José, Formación de la Constitución y jurisdicción constitucional. Fundamentos de la democracia constitucional (Madrid, Tecnos, 1998).

Aldunate Lizana, Eduardo, Jurisprudencia constitucional 2006-2008. Estudio selectivo (Santiago, LegalPublishing, 2009).

Bellamy, Richard, Political Constitutionalism (Cambridge, Cambridge University Press, 2007).

Brilmayer, Lea, The Jurisprudencia of Article III: Perspectives on the "Case or Controversy" Requirement en Harvard Law Review 93 (1979) 2.

Caamaño Domínguez, Francisco - Gómez Montoro, Angel J. - Medina GueRRERO, Manuel - REQUEJO PAGÉs, Juan Luis, Jurisdicción y procesos constitucionales (Madrid, McGraw-Hill, 1997).

Caenegem, R.C. van, An historical introduction to Western Constitutional Law (Cambridge, Cambridge University Press, 1996).

Carré de Malberg, R., Teoría general del Estado (México, Fondo de Cultura Económica, 2000).

Chayes, Abram, The Role of the Judge in Public Law Litigation, en Harvard Law Review, 89 (mayo, de1976) 7.

Damaska, Mirjan, Las caras de la justicia y el poder del Estado. Análisis comparado del proceso legal (Santiago, Editorial Jurídica de Chile, 2000).

Damaska, Mirjan, Structures of Authority and Comparative Criminal Procedure, en The Yale Law Journal, 84 (enero de 1975) 3.

Epstein, Lee - Knight, Jack - Shvetsova, Olga, The Role of Constitutional Courts in the Establishment and Maintenance of Democratic Systems of Government, en Law \& Society Review, 35 (2001) 1.

Fiss, Owen M., The Bureaucratization of the Judiciary, en The Yale Law Journal, 92 (julio de 1983) 8.

Gómez Bernales, Gastón, La reforma constitucional a la jurisdicción constitucional, en ZúNíiga Urbina, Francisco, Reforma constitucional (Santiago, LexisNexis, 2005).

HeRnÁNDEz Ramos, Mario, El nuevo trámite de admisión del recurso de amparo constitucional (Madrid, Reus, 2009).

JaCKson, Vicki C. - Tushnet, Mark, Comparative Constitutional Law (2a ed., Nueva York, Foundation Press, 2006).

JellineK, Georg, Teoría general del Estado (México, Fondo de Cultura Económica, 2000). 
Ministerio del Interior, Actas Oficiales del Proyecto de Nueva Constitución Politica de la República (Santiago, Imprenta Universitaria, 1926).

Ruiz Miguel, Alfonso, Modelo americano y modelo europeo de justicia constitucional, en Doxa. Cuadernos de Filosofía del Derecho 23 (2000).

Sabel, Charles F. - Simon, William H., Destabilization Rights: How Public Law Litigation Succeeds, en Harvard Law Review, 117 (febrero, 2004) 4.

Shapiro, David L., Some Thoughts on Intervention before Courts, Agencies and Arbitrators, en Harvard Law Review, 81 (febrero de 1968) 4, 721-772.

Silva Bascuñán, Alejandro, Tratado de Derecho Constitucional (Santiago, Editorial Jurídica de Chile, 1963).

Sola, Juan Vicente, Control judicial de constitucionalidad (Buenos Aires, AbeledoPerrot, 2001).

Torres Muro, Ignacio, La legitimación en los procesos constitucionales (Madrid, Reus, 2007).

Torres Muro, Ignacio, La legitimación en los procesos constitucionales (Madrid, Reus, 2007).

Tsebelis, George, Veto Players: How Political Institutions Work (Princeton, Princeton University Press, 2002).

Tushnet, Mark, Taking the Constitution Away from the Courts (Princeton, Princeton University Press, 1999).

Zagrebelsky, Gustavo, Principios y votos. El Tribunal Constitucional y la politica (Madrid, Trotta, 2008).

ZúNiga Urbina, Francisco, Acciones de inaplicabilidad e inconstitucionalidad. Doctrina y jurisprudencia del Tribunal Constitucional sobre temas procesales (Santiago, AbeledoPerrot, 2010). 